\title{
THE EFFECT OF POSITIONAL ISOMERISM OF PROPANEDIOL ON THE FORMATION OF COBALT OXIDES
}

\author{
THOMAS DIPPONG ${ }^{a}$, FIRUTA GOGA $^{\mathrm{b}}$, ALEXANDRA AVRAM ${ }^{\mathrm{b}}$
}

\begin{abstract}
This paper focuses on a comparative analysis between the carboxylate precursors obtained through the redox reaction between cobalt nitrate and 1,2-propanediol, and cobalt nitrate with 1,3-propanediol, respectively. The formation of the lactate and malonate precursors was followed with thermal analysis, FTIR spectrometry and acido-basic analysis (conductometric/ potentiometric titrimetry). The decomposition of the carboxylate precursors and the formation rate of cobalt oxides were observed by X-ray diffractometry and FTIR spectrometry, following advanced thermal treatments at $500^{\circ} \mathrm{C}$, $800^{\circ} \mathrm{C}$ and $1000^{\circ} \mathrm{C}$, with a pretreatment at $300^{\circ} \mathrm{C}$. The differences between the two positional diol isomers are comparatively discussed.
\end{abstract}

Keywords: lactate, malonate, $\mathrm{Co}_{3} \mathrm{O}_{4}$, electrometric titrimetry, thermal treatment

\section{INTRODUCTION}

Transitional metal oxides include a large spectrum of inorganic materials with distinctive compositions and morphologies, leading to a wide variety of characteristics [1,2].

Cobalt oxides have drawn increasing attention due to their unique size, shape dependent properties [3] and diverse spectrum of applications such as, ethylene oxidation [1], energy storage and conversion, glucose detection, water spitting [4], catalytic oxidation [5], lithium ion batteries [6], as a contrasting agent for magnetic resonance, in biomedical sensors [3] and targeted drug delivery $[3,4,7]$.

\footnotetext{
a Technical University of Cluj-Napoca, Faculty of Sciences North University Center at Baia Mare, Department of Chemistry and Biology, 76 Victoriei Street, 430122 Baia Mare, Romania

b Babeş-Bolyai University, Faculty of Chemistry and Chemical Engineering, 11 Arany Janos Street., RO-400028, Cluj-Napoca, Romania,

*Corresponding author: fgoga@chem.ubbcluj.ro
} 
When falling in the nanosized range, cobalt oxides have been proven to exhibit even more attractive applications [8-9]. Up until now, cobalt oxide in the form of nanoparticles has been obtained through a number of methods, namely, thermal decomposition [4,10], sol-gel [2], hydrothermal [11], solvothermal [11], co-precipitation [12], photochemical synthesis, reversed micelles [13], microwave heating [9] etc. All these systems, comprising cobalt oxides of various compositions and stoechiometry, rely on the thermodinamic stability of $\mathrm{Co}^{2+} / \mathrm{Co}^{3+}$ oxidation states.

In solution-phase synthesis, the main cobalt oxide crystal phase is $\mathrm{Co}_{3} \mathrm{O}_{4}$, followed by the less common $\mathrm{CoO}$ [1], both states being the most stable [8]. The greater thermodinamic stability of $\mathrm{Co}_{2} \mathrm{O}_{3}$ followed by the instant reducibility of $\mathrm{CoO}$ to $\mathrm{Co}$, makes the synthesis of $\mathrm{CoO}$ in pure phase difficult. Relevant literature [14-15] studies the synthesis of single cobalt oxides and compound oxide nanoparticles through the redox reaction of metal salts with various diols, in different molar ratios.

This paper presents the synthesis of cobalt oxide precursors by the redox reaction between cobalt nitrate and 1,2-propandiol respectively 1,3propandiol and the characterization of the precursors by Thermal analysis, FTIR and study of acido-basic properties, using conductometric and $\mathrm{pH}$-metric titrations. Titration techniques have the advantage of ease of implementation, cost-effectiveness and accuracy. Electrometric titrations also have the advantage of automation, increasing the analysis throughput and securing the consistent quality of the results.

\section{RESULTS AND DISCUSSION}

Previous studies have shown the redox reactions between cobalt nitrate and diols (ethylene glycol, 1,2 propanediol, 1,3 propanediol) leads to the formation of coordination compounds of $\mathrm{Co}$ (II) with the carboxylate anions, diols' oxidation product, where only the primary $\mathrm{C}-\mathrm{OH}$ groups participate. The secondary $\mathrm{C}-\mathrm{OH}$ groups are not involved in the redox reactions. Thus, the oxidation of 1,2 propanediol leads, in particular working conditions, to the formation of lactate anions, according to the following equations (Scheme 1)

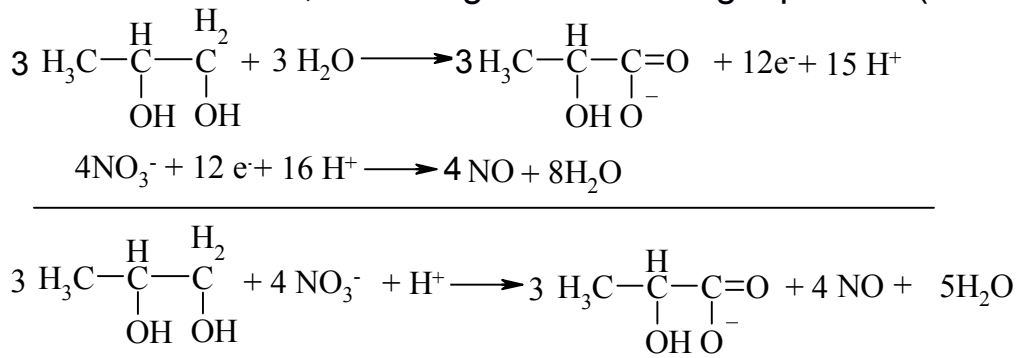

Scheme 1. The redox reaction leading to the formation of the lactate precursor 
Similarly, the redox reaction between nitrate and 1,3-propanediol leads to the formation of malonate anions (Scheme 2).

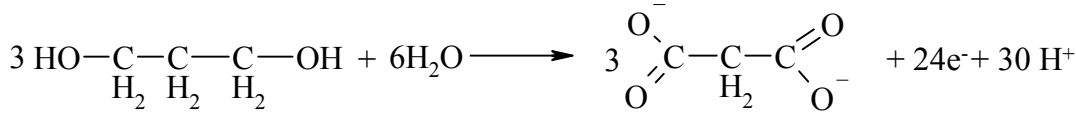

$$
\begin{aligned}
& 8 \mathrm{NO}_{3}^{-}+24 \mathrm{e}^{-}+32 \mathrm{H}^{+} \longrightarrow 8 \mathrm{NO}+16 \mathrm{H}_{2} \mathrm{O}
\end{aligned}
$$

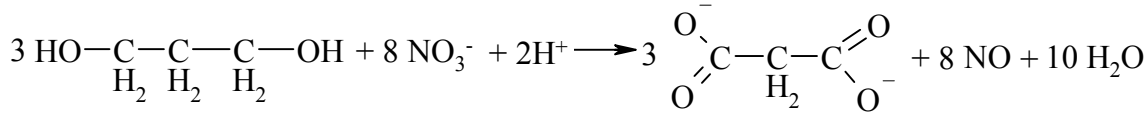

Scheme 2. The redox reaction leading to the formation of the malonate precursor

The reaction is promoted by the formation of the coordination compounds between the resulted carboxylate ions and the $\mathrm{Co}(\mathrm{II})$ cations (the diol does not only interact with $\mathrm{HNO}_{3}$ ).

The redox reaction between $\mathrm{Co}\left(\mathrm{NO}_{3}\right)_{2}$ şi 1,2-PG, and $\mathrm{Co}\left(\mathrm{NO}_{3}\right)_{2}$ and 1,3-PG, respectively, was studied by thermal analysis. This entails the thin layer deposition of cobalt nitrate-diol solutions onto Pt pans, followed by an air heating up to $500^{\circ} \mathrm{C}$. Figure 1 presents the thermal curves for the 1,2 propanediol, and 1,3 propanediol containing mixtures.

The presented DTA thermal curves show two exothermic processes. The first exothermic process, around $170^{\circ} \mathrm{C}$, is attributed to the development of the $\mathrm{Co}\left(\mathrm{NO}_{3}\right)_{2}-1,2 \mathrm{PG}$ redox reaction. The reaction unfolds integraly with the formation of a single oxidation product, respectively, of Co (II) combinations (visualy confirmed by the evolving of the brown gas-nitrogen oxides). The second effect, around $280^{\circ} \mathrm{C}$, corresponds to the oxidative decomposition of cobalt lactate into cobalt oxide.
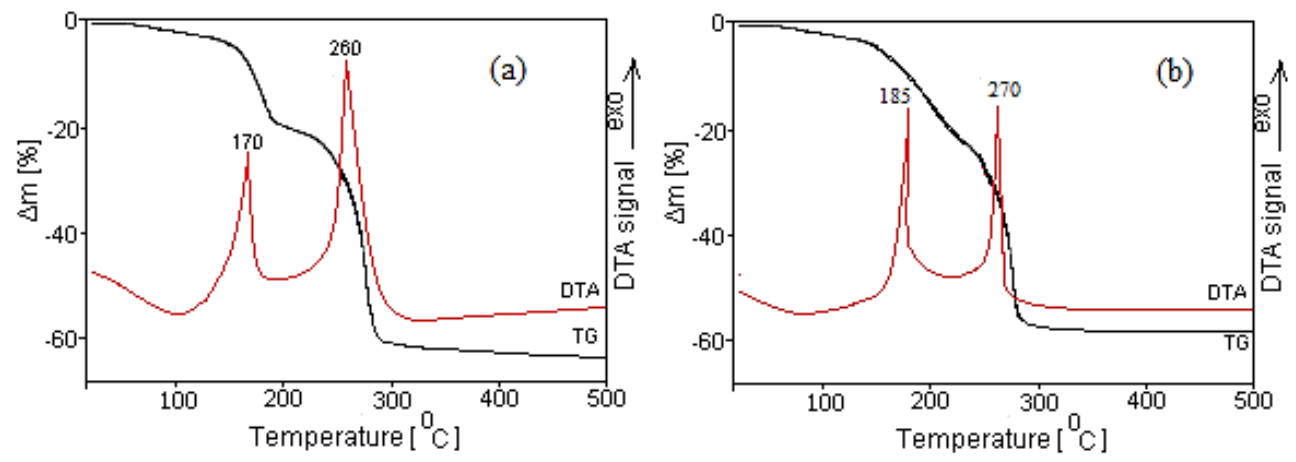

Figure 1. Thermal curves for the $\mathrm{Co}\left(\mathrm{NO}_{3}\right)_{2}-1,2 \mathrm{PG}$ (a) and $\mathrm{Co}\left(\mathrm{NO}_{3}\right)_{2}-1,3 \mathrm{PG}$ (b) solutions 
In the case of 1,3 propanediol, the exothermic effects are slightly carried towards higher temperatures, the formation of cobalt malonate occuring at $185^{\circ} \mathrm{C}$, and its decomposition at $270^{\circ} \mathrm{C}$. Given the usage of 1,3 propandiol, the mass loss presented on the TG curve amounts to $21 \%$ for the first process, and $17 \%$ for the second one, a half reduced loss being observed in the case of utilizing a primary diol as opposed to a primarysecondary one.

In the case of 1,2 propanediol, the mass loss seen on the TG curve is $20 \%$ for the first process, and $41 \%$ for the second one.

Following the thermal analysis, the optimal carboxylate precursors synthesis temperature was established at $140^{\circ} \mathrm{C}$. The products obtained at this temperature were characterized by FTIR analysis (fig 2). FTIR spectra of the lactate precursor obtained from 1,2 propanediol and malonate, and 1,3 propanediol, respectively, present all the characteristic bands of the carboxylate anions coordinated at metalic ions: $v_{\text {as }}\left(C O O^{-}\right)$la $1646 \mathrm{~cm}^{-1}$,

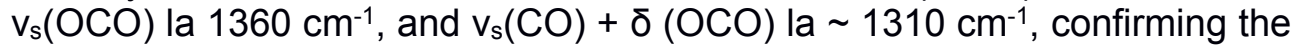
formation of this type of compound [18]. In the case of the lactate procursor's spectra, an intense band can be observed from $1070 \mathrm{~cm}^{-1}$, characteristic to the secondary $\mathrm{C}-\mathrm{OH}$ group (1,2-propandiol) that does not take part in the redox reaction, thus confirming the formation of the lactate precursor. The absence of bands characteristic to $\mathrm{O}-\mathrm{H}$ groups suggests the formation of the carboxylate dianion (malonate) [17]. The bands at $2974 \mathrm{~cm}^{-1}, 2940 \mathrm{~cm}^{-1}$ and $2870 \mathrm{~cm}^{-1}$ are characteristic to the stretching vibrations of the $\mathrm{C}-\mathrm{H}$ bonds from- $\mathrm{CH}_{3}[16-17]$.

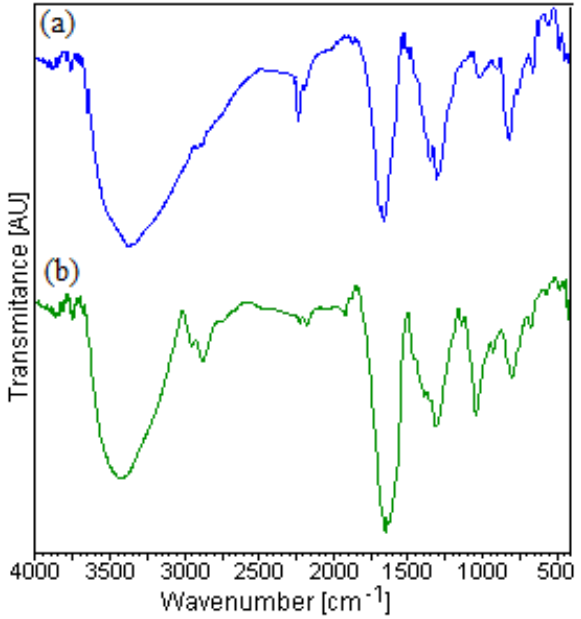

Figure 2. FTIR spectrum of the lactate (a), malonate (b) precursors synthesized at $140^{\circ} \mathrm{C}$ 
Figure 3 presents the comparative thermal curves (TG, DTA) for the decomposition of lactate and malonate precursors, up to $1000^{\circ} \mathrm{C}$. The $20 \%$ mass loss up to $\sim 210^{\circ} \mathrm{C}$ can be attributed to the elimination of water from the complex combination. The one from the $220-300^{\circ} \mathrm{C}$ temperature range $(42 \%$ for 1,2 propanediol and $21 \%$ for 1,3 propanediol), accompanied by an acute exothermic effect (at $280^{\circ} \mathrm{C}$ for 1,2-propanediol and $240^{\circ} \mathrm{C}$ for 1,3 propanediol, corresponds to the oxidative decomposition of formed complex combinations (lactate, malonate). This decomposition takes place with an in-situ generation of a reductive atmosphere, causing the reduction of $\mathrm{Co}$ (II) to metallic $\mathrm{Co}$, followed by its reoxidation to a weakly crystallized oxide with an increased reactivity [21]. Between $950-1000^{\circ} \mathrm{C}$, a final mass loss (4\%) can be observed, corresponding to the transformations in the oxidic system, the reduction of $\mathrm{Co}_{3} \mathrm{O}_{4}$ to $\mathrm{CoO}$, an endothermic effect on the DTA curve $\left(950-960^{\circ} \mathrm{C}\right)$.
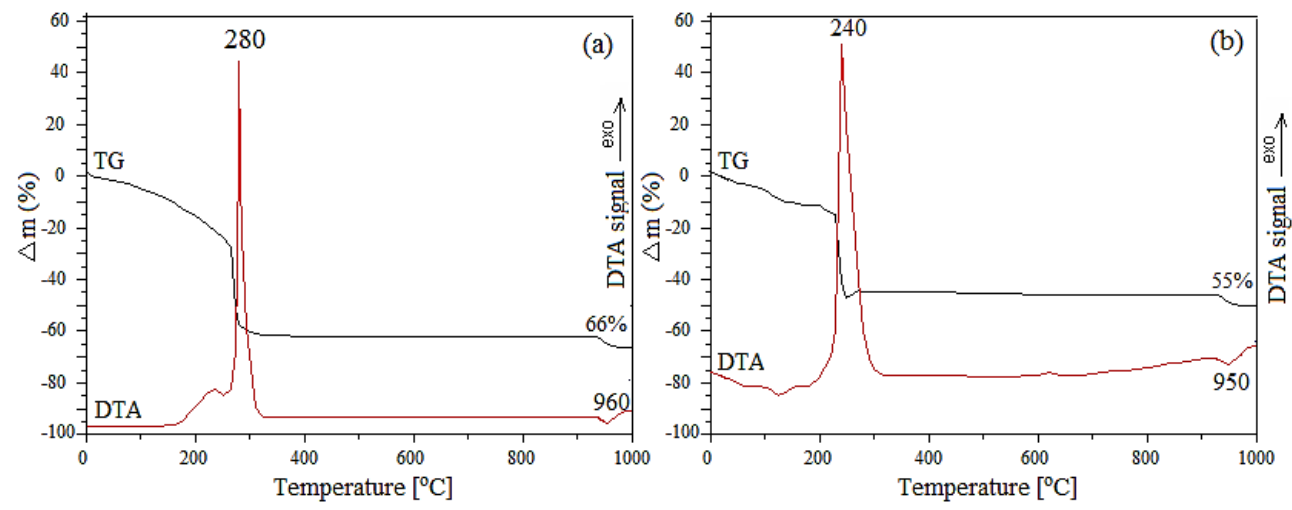

Figure 3. Thermal behaviour of the lactate (a) and malonate (b) precursors synthesized at $140^{\circ} \mathrm{C}$

In order to establish if the precursor is a $\mathrm{Co}$ (II) lactate or a $\mathrm{Co}$ (II) hydroxylactate, and malonate or hydroxymalonate we have studied the acidobasic properties, by using conductometric and $\mathrm{pH}$-metric titrations.

The processes that can take place in the precursor treated with a $\mathrm{HCl}$ solution, and $\mathrm{NaOH}$ respectively, are presented in schemes 3 and 4 . 


$$
\begin{array}{c|c}
\text { Consum } \mathrm{H}^{+} & \text {Consum } \mathrm{OH}^{-} \\
\mathrm{C}_{3} \mathrm{H}_{5} \mathrm{O}_{3}^{-}+\mathrm{H}_{\mathrm{a}}^{+} \longrightarrow \mathrm{C}_{3} \mathrm{H}_{6} \mathrm{O}_{3} & \mathrm{Co}^{2+}+2 \mathrm{OH}^{-} \longrightarrow \mathrm{Co}(\mathrm{OH})_{2} \\
\mathrm{CoOH}^{+}+\mathrm{H}_{\mathrm{a}}^{+} \longrightarrow \mathrm{Co}^{2+}+\mathrm{H}_{2} \mathrm{O} & \mathrm{CoOH}{ }^{+}+\mathrm{OH}^{-} \longrightarrow \mathrm{Co}(\mathrm{OH})_{2}
\end{array}
$$

Scheme 3. The processes that can take place in the precursor (lactate) treated with $\mathrm{HCl}$ (left) and with $\mathrm{NaOH}$ (right)

$$
\begin{array}{l|l}
\mathrm{C}_{3} \mathrm{H}_{2} \mathrm{O}_{4}^{2-}+2 \mathrm{H}^{+} \longrightarrow \mathrm{C}_{3} \mathrm{H}_{4} \mathrm{O}_{4} & \\
\mathrm{C}_{3} \mathrm{H}_{3} \mathrm{O}_{4}^{-}+\mathrm{H}_{\mathrm{a}}^{+} \longrightarrow \mathrm{C}_{3} \mathrm{H}_{4} \mathrm{O}_{4} & \mathrm{Co}^{2+}+2 \mathrm{OH}^{-} \longrightarrow \mathrm{Co}\left(\mathrm{OH}_{2}\right. \\
\mathrm{CoOH}^{+}+\mathrm{H}_{\mathrm{a}}^{+} \longrightarrow \mathrm{Co}^{2+}+\mathrm{H}_{2} \mathrm{O} & \mathrm{CoOH}^{+}+\mathrm{OH}^{-} \longrightarrow \mathrm{Co}\left(\mathrm{OH}_{2}\right.
\end{array}
$$

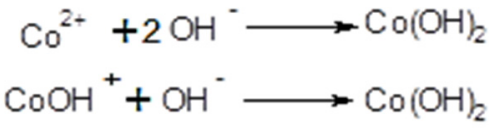

Scheme 4. The processes that can take place in the precursor (malonate) treated with $\mathrm{HCl}$ (left) and with $\mathrm{NaOH}$ (right)

The consumed acid amount is calculated from the difference between the initial and the unreacted $\mathrm{HCl}$ volume (corresponding to the first point of equivalence). The utilized amount of $\mathrm{NaOH}$ is evaluated through the difference between the $\mathrm{NaOH}$ volume corresponding to the second point of equivalence and the volume of initial $\mathrm{HCl}$. When the consumed $\mathrm{HCl}$ quantity (for the protonation of the lactate ion) is equal to the quantity of consumed $\mathrm{NaOH}$ (for the precipitation of $\mathrm{Co}(\mathrm{II})$ to $\left.\mathrm{Co}(\mathrm{OH})_{2}\right)\left(\mathrm{H}^{+} / \mathrm{OH}^{-1}=1\right)$, it can be considered that cobalt (II) lactate $\left(\mathrm{Co}\left(\mathrm{C}_{3} \mathrm{H}_{5} \mathrm{O}_{3}\right)_{2}\right)$ is the precursor. Cobalt (II) hydroxylactate precursor $\left(\mathrm{Co}(\mathrm{OH}) \mathrm{C}_{3} \mathrm{H}_{5} \mathrm{O}_{3}\right)$ is formed when the volume of consumed $\mathrm{HCl}$ (for the precipitation of lactate and hydroxide ions) is double $\left(\mathrm{H}^{+} / \mathrm{OH}^{-}=2\right)$ when compared to the consumed $\mathrm{NaOH}$ (for the precipitation of $\mathrm{Co}(\mathrm{OH})$ to $\left.\mathrm{Co}(\mathrm{OH})_{2}\right)$. The precursor of cobalt malonate $\left(\mathrm{CoC}_{3} \mathrm{H}_{2} \mathrm{O}_{4}\right)$, has a similar formation, when the quantity of consumed $\mathrm{HCl}$ is equal with the quantity of consumed $\mathrm{NaOH}$ (for the precipitation of $\mathrm{Co}(\mathrm{II})$ as $\left.\mathrm{Co}(\mathrm{OH})_{2}\right)$. To confirm the formation of the hydroxycarboxylate anion (lactate), and dicarboxylate (malonate), neutral, basic or hydroxyde, studies on the acido-basic properties were carried out (conductometric and $\mathrm{pH}$ metric titrations) Figure 4 presents the conductometric titration (Figure 4a), and $\mathrm{pH}$-metric titration (Figure $4 \mathrm{~b}$ ) curves of the acid solutions of the sample with 1,2 propanediol and $\mathrm{HCl}$ solution (volume used to disolve the precursor and process the experimental results). 

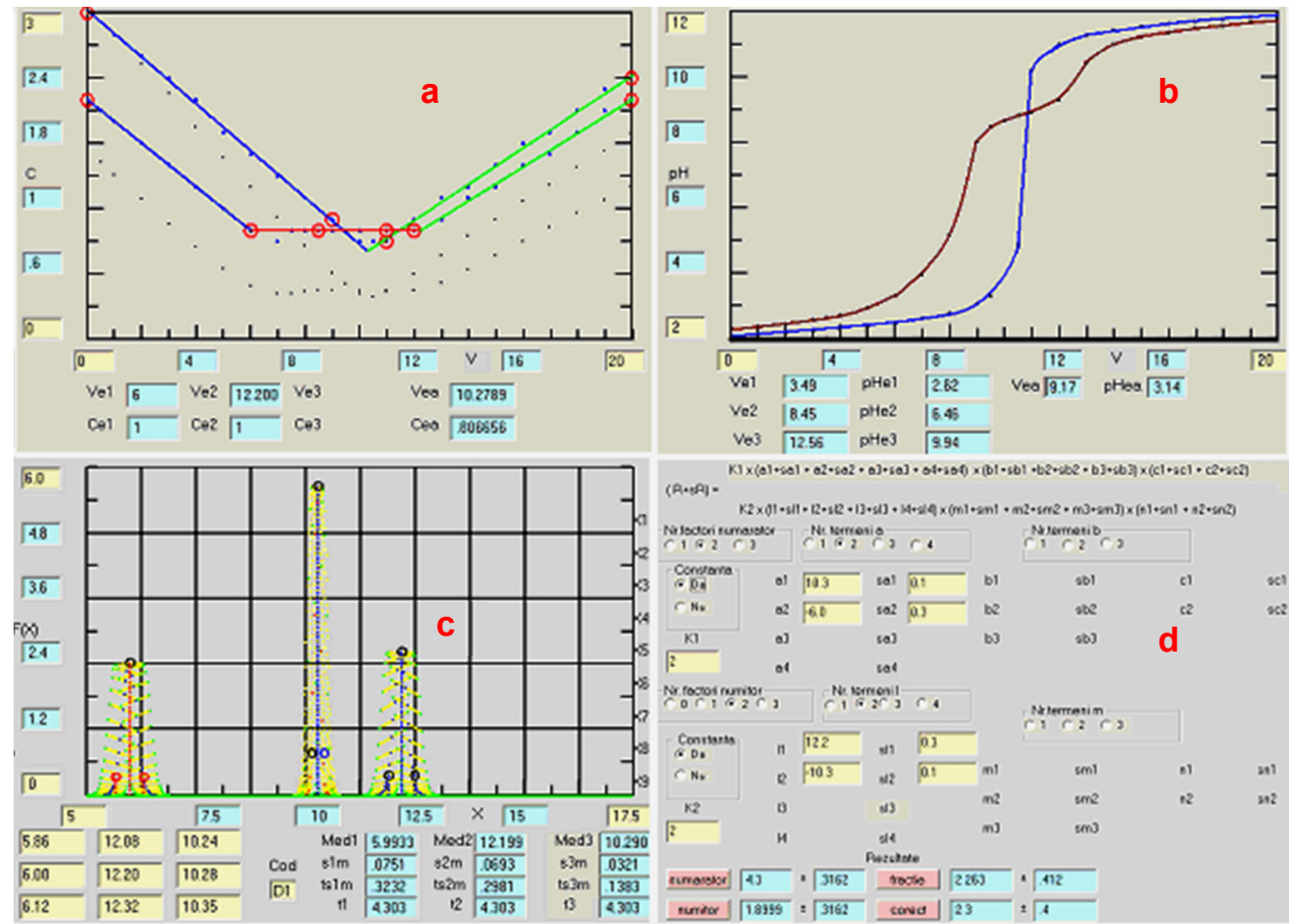

Figure 4. Conductometric titration curve (a), pH-metric titration curve (b), calculation of the medium equivalence volume (c), calculation of the reaction ratio (d) for the 1,2 propanediol sample

Figure $4 \mathrm{c}$ shows the statistical calculus method for the equivalence volumes, while figure $4 d$, presents the statistic calculus method for the consumed acid/ consumed base ratios from the equivalence volumes. In the case of using 1,2 propanediol, a mixture of neutral and basic salts is obtained, whereas in the case of 1,3 propanediol isomer, only hydroxymalonate is obtained. Similarly, the acido-basic curves in the case of 1,3-propanediol are presented (Figure $5 a$ and $5 b$ ), followed by the statistical calculation of the acid/ base ratio (Figure $5 c$ and $5 d$ ). 

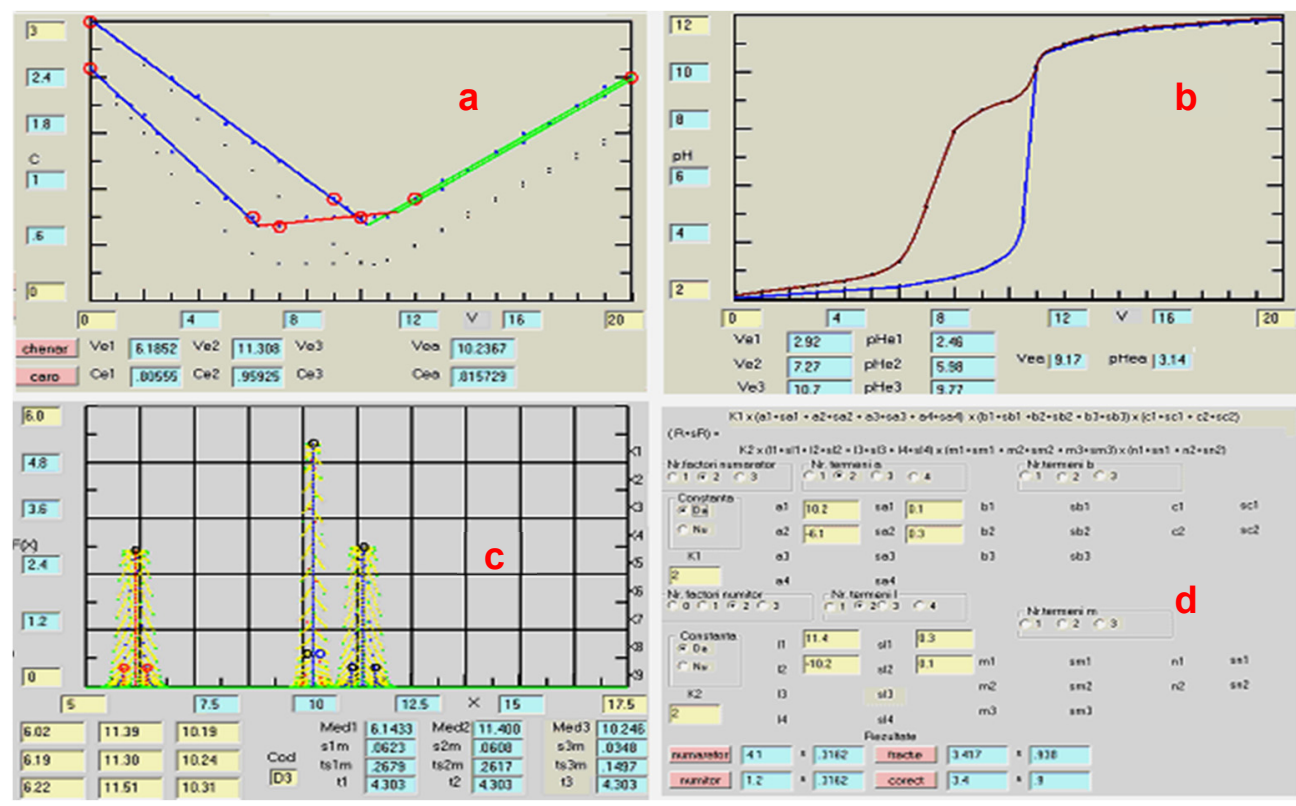

Figure 5. Conductometric titration curve (a), pH-metric titration curve (b), calculation of the medium equivalence volume (c), calculation of the reaction ratio (d) for the 1,3 propanediol sample

The results obtained following the conductometric and $\mathrm{pH}$-metric titrations are presented in table 1.

Table 1. $\mathrm{H}^{+} / \mathrm{OH}^{-}$molar ratios and the compounds formed following the acido-basic titrations

\begin{tabular}{|l|c|c|c|}
\hline \multicolumn{3}{|c|}{ Experimental molar ratio $\mathrm{H}^{+} / \mathrm{OH}^{-}$} & Corresponding compound \\
\cline { 1 - 2 } Sample obtained from & Conductometric & pH-metric & $\begin{array}{c}\mathrm{Co}\left(\mathrm{C}_{3} \mathrm{H}_{5} \mathrm{O}_{3}\right)_{2} \\
(\mathrm{CoOH}) \mathrm{C}_{3} \mathrm{H}_{5} \mathrm{O}_{3}\end{array}$ \\
\hline 1.2 propanediol & $2.3 \pm 0,4$ & $1.5 \pm 0.3$ & $\mathrm{n}(\mathrm{CoOH})_{2} . \mathrm{CoC}_{3} \mathrm{H}_{2} \mathrm{O}_{4}$ \\
\hline 1.3 propanediol & $4.0 \pm 0.2$ & $4,2 \pm 0.3$ & $\mathrm{n}$ \\
\hline
\end{tabular}

The acido-basic properties of the synthesized compounds confirm the results of thermmal analysis and FTIR, advocating that the redox reaction forms carboxylate or hydroxycarboxylate compounds, that coordinate $\mathrm{Co}$ (II) ions in the form of a compound with either a basic or a neutral character.

The precursor was thermally decomposed at $300^{\circ} \mathrm{C}$ for 6 hours and then annealed for 3 hours at $500^{\circ} \mathrm{C}$, at $800^{\circ} \mathrm{C}$ and at $1000^{\circ} \mathrm{C}$. Following the thermal analysis, it was observed that the thermal decomposition of the carboxylate precursors occured up until $300^{\circ} \mathrm{C}$ with the formation of cobalt 
oxides through the in situ generation of a reductive atmosphere $(\mathrm{C}, \mathrm{CO})$ depending on the nature of the presumed complex combination. The reductive atmosphere can be influenced by the nature of the diol and the manner in which the decomposition (thermal treatment) takes place. The annealing products were studied by XRD analysis (fig. 6). Following the $500^{\circ} \mathrm{C}$ decomposition of cobalt lactate, a mixture of cobalt oxides $\left(\mathrm{CoO}\right.$ and $\left.\mathrm{Co}_{3} \mathrm{O}_{4}\right)$ is formed. At $800^{\circ} \mathrm{C} \mathrm{Co}_{3} \mathrm{O}_{4}$ is obtained as a single phase, while at $1000^{\circ} \mathrm{C}$, CoO forms as a single phase (JCPDS 75-0393 chart [18]). In the case of cobalt malonate decomposition, $\mathrm{Co}_{3} \mathrm{O}_{4}$ is obtained as a single, crystalline phase (JCPDS $42-1467$ chart [18]), both at 500 and $800^{\circ} \mathrm{C}$, while at $1000^{\circ} \mathrm{C}, \mathrm{CoO}$ becomes the unique crystalline phase. The reduction of $\mathrm{Co}_{3} \mathrm{O}_{4}$ to $\mathrm{CoO}$ takes place following the reaction:

$$
\mathrm{Co}_{3} \mathrm{O}_{4} \rightarrow 3 \mathrm{CoO}+1 / 2 \mathrm{O}_{2}
$$
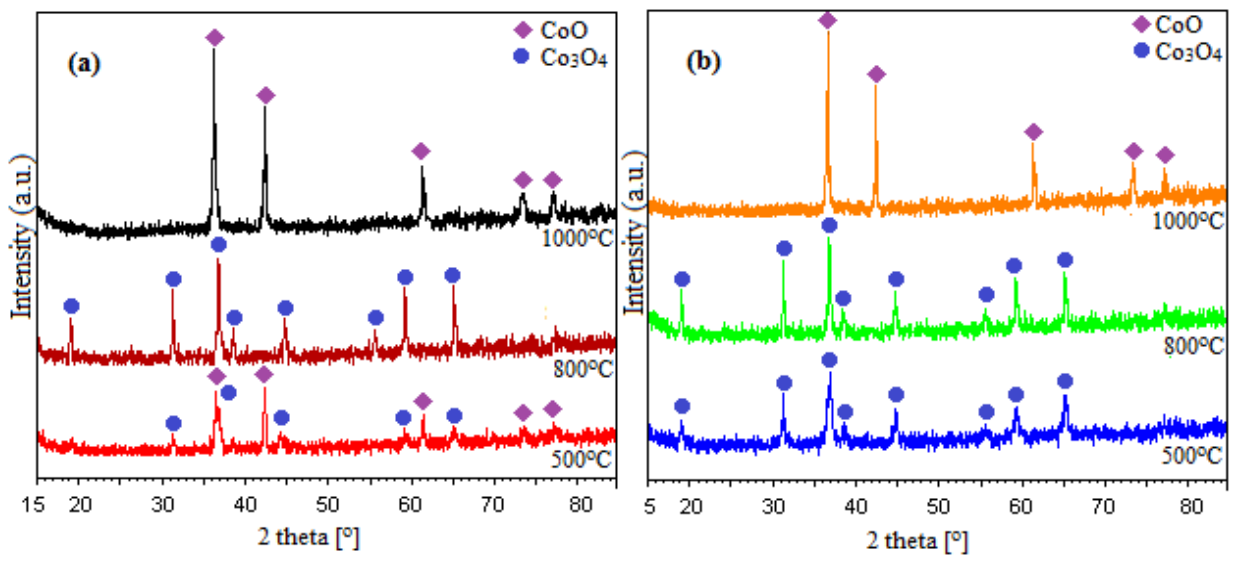

Figure 6. XRD difractogram of samples obtained from 1-2-propanediol (a), 1,3 -propanediol (b) at $500^{\circ} \mathrm{C}, 800^{\circ} \mathrm{C}$ and $1000^{\circ} \mathrm{C}$

The average crystallite size (D) of $\mathrm{CoO}$ and $\mathrm{CO}_{3} \mathrm{O}_{4}$ was calculated from the XRD data using Debye-Scherrer formula $\left(D=C \cdot \lambda / \beta_{1 / 2} \cdot \cos \theta\right)[19]$ and is presented in table 2 .

Table 2. Average diameters of nanoparticles calculated with Scherrer equation

\begin{tabular}{|c|c|c|c|c|}
\hline & \multicolumn{4}{|c|}{ Average diameter $/ \mathrm{nm}$} \\
\hline \multirow{2}{*}{ Temperature $/{ }^{\circ} \mathrm{C}$} & \multicolumn{2}{|c|}{ din 1.2 propandiol } & din 1.3 propandiol \\
\cline { 2 - 5 } & $\mathrm{CoO}$ & $\mathrm{Co}_{3} \mathrm{O}_{4}$ & $\mathrm{CoO}$ & $\mathrm{Co}_{3} \mathrm{O}_{4}$ \\
\hline 500 & 20 & 23 & - & 26 \\
\hline 800 & & 28 & & 30 \\
\hline 1000 & 32 & - & 35 & - \\
\hline
\end{tabular}


According to the data in table 2, the dimension of the nanoparticles increases with the increase in temperature and with that of the crystallization degree. In addition, purer oxides with larger nanoparticles are obtained from 1,3 propanediol when compared to those synthesized from 1,2 propanediol.

\section{CONCLUSIONS}

The redox reaction $\mathrm{Co}\left(\mathrm{NO}_{3}\right)_{2}-1,2$-propandiol and $\mathrm{Co}\left(\mathrm{NO}_{3}\right)_{2}-1,3-$ propandiol, as evidenced by thermal analysis, takes place in the range of $160-190^{\circ} \mathrm{C}$. The cobalt lactate and cobalt malonate formation of the redox reaction was confirmed by means of FT-IR spectrometry, thermal analysis and acido-basic analysis (conductometric and $\mathrm{pH}$-metric). All techniques have evidenced the formation of coordination compounds of $\mathrm{Co}$ (II) with the lactate anions, resulted through 1,2-propandiol oxidation. According to the study of acido-basic properties of the product obtained from 1,2-propandiol, a mixture of $\mathrm{Co}$ (II) lactate and $\mathrm{Co}$ (II) hydroxylactate was obtained, while from 1,3-propandiol only cobalt malonate was synthesized. By thermal treatment of this product at $500^{\circ} \mathrm{C}$, through the decomposition of cobalt lactate, a mixture of $\mathrm{CoO}$ and $\mathrm{Co}_{3} \mathrm{O}_{4}$ is obtained, while at at $800^{\circ} \mathrm{C}$ only the $\mathrm{Co}_{3} \mathrm{O}_{4}$ crystalline phase results, phase that at $950^{\circ} \mathrm{C}$ reduces to the well crystallized $\mathrm{CoO}$. In the case of cobalt malonate decomposition, $\mathrm{Co}_{3} \mathrm{O}_{4}$ results as a single phase, while at $1000^{\circ} \mathrm{C}$ the unique phase is $\mathrm{CoO}$, the crystallization degree increasing with the increase in temperature. The size of nanoparticles increases with temperature, where $\mathrm{Co}_{3} \mathrm{O}_{4}$ obtained from 1,2 propanediol at $800^{\circ} \mathrm{C}$ has $28 \mathrm{~nm}$, and from 1,3 propanediol, $30 \mathrm{~nm}$. In a similar manner, the dimensions of $\mathrm{CoO}$ obtained through the decomposition of cobalt lactate, following the $1000^{\circ} \mathrm{C}$ thermal treatment, increases from 32 to $35 \mathrm{~nm}$ from the decomposition of malonate. In conclusion, it can be stated that the position of the second $\mathrm{OH}$ group can influence the conditions related to the formation of the carboxylic precursor, as well as the nature of oxides formed by advanced treatments.

\section{EXPERIMENTAL SECTION}

The reagents used in synthesis were: $\mathrm{Co}\left(\mathrm{NO}_{3}\right)_{2} \cdot 6 \mathrm{H}_{2} \mathrm{O}$ and 1,2 propanediol respectively 1,3-propandiol of purity p.a. (Merk). The synthesis method consists in dissolving cobalt nitrate in the corresponding 1,2PG respectively 1,3-propanediol in stoichiometric ratio, amount followed by controlled heating at $140^{\circ} \mathrm{C}$. At these temperatures, the redox reaction 
begins accompanied by nitrogen oxide emission (brown-reddish gas). The isolated reaction products were maintained at $140^{\circ} \mathrm{C}$ until the emission of brown gas stops (reaction end). The powder obtained at $140^{\circ} \mathrm{C}$ was washed with acetone for removing of the reactant excess. The obtained products were characterized by thermal analysis, FT-IR spectrometry and conductometric/ $\mathrm{pH}$-metric acido-basic titrations

For the conductometric and potentiometric titrations $0.2 \mathrm{mmoli} \mathrm{Co}(\mathrm{II})$ were used, adding volumes of $10,0 \mathrm{~cm}^{3} \mathrm{HCl} 0.1 \mathrm{M}$ and subjected to titrations with $\mathrm{NaOH} 0.1 \mathrm{M}$. The acido-basic properties of the precursors were studied through conductometric and $\mathrm{pH}$-metric titrations using a Crison MM41 multimeter. The formation process of cobalt oxides was followed with thermogravimetry (TG), derivative thermogravimetry (DTG) and differential thermal analysis (DTA) using a SDT Q600 type instrument, in air up to $1000^{\circ} \mathrm{C}$ at $10^{\circ} \mathrm{C} \mathrm{min}{ }^{-1}$ and alumina standards. The FTIR spectra were recorded on $1 \% \mathrm{KBr}$ pellets using a Spectrum BX II spectrometer. The XRD patterns were recorded using a high resolution Bruker D8 Advance diffractometer with $\mathrm{Cu}\left(\lambda_{\text {cuka1 }}=1,54056 \AA\right)$ radiation.

\section{REFERENCES}

1. L. Qiao, M.T. Swihart, Advances in Colloids and Interface Science, 2017, 244, 199.

2. H.M. Khaled, Polymer Composites, 2016, 37, 1881.

3. E. Papis, F. Rossi, M. Raspanti, I. Dalle-Donne, G. Colombo, A. Milzani, G. Bernardini, R. Cornati, Toxicology Letters, 2009, 189, 253.

4. H. Heli, J., Pishahang, Electrochimica Acta, 2014, 123, 518.

5. M. Allen, D. Willits, M. Young, T. Douglas, Inorganic Chemistry, 2003, 42, 6300.

6. S. Kundu, M. Jayachandran, Journal of Nanoparticle Research, 2013, 15, 1.

7. Q.A. Pankhurst, J. Connolly, S.K. Jones, J. Dobson, Journal of Physiscs D: Applied Physics, 2003, 36, 167.

8. R. Manigandan, K. Giribabu, R. Suresh, L. Vija Yalakshmi, V. Narayanan, Chemical Science Transactions, 2013, 2, 47.

9. A. Ashok, A. Kumar, R.R. Bhosale, M.A.H. Saleh, U.K. Ghosh, M. Al-Marri, F.A. Almomani, M.M. Khader, Ceramic International, 2016, 42, 12771.

10. S. Chattopadhyay, S.P. Chakraborty, D. Laha, R. Baral, P. Pramanik, S. Roy, Cancer Nanotechnology, 2012, 3, 13.

11. K. Slinko, G. Szabo, M. Zrinyi, Journal of Nanoscience and Nanotechnology, 2011, 11, 1.

12. K.F. Wadekar, K.R. Nemade, S.A. Waghuley, Research Journal of Chemical Sciences, 2017, 7, 53. 
13. M. Yarestani, A.D. Khalaji, A. Rohani, D. Das, Journal of Sciences, Islamic Republic of Iran, 2014, 25, 339.

14. Q. Liu, X. Guo, J. Chen, J. Li, W. Song, W. Shen, Nanotechnology, 2008, 19, 365608.

15. C. Luna, M. del Puerto Morales, C.J. Serna, M. Vazquez, Nanotechnology, 2003, 14, 268.

16. R. Prasad, Sulaxna and A. Kumar, Journal of Thermal Analysis and Calorimetry, 2005, 81, 441.

17. Vencat Narayan R., Kanniah V., Dhathathreyan A., Journal of Chemical Sciences, 2006, 118, 179.

18. Joint Committee on Powder Diffraction Standards. International Center for Diffraction Data, 1999.

19. Klug HP, Alexander LE. X-Ray Diffraction Procedures. 2nd ed. John Wiley \& Sons Inc, 1974. 